\title{
COMPARISON OF THE DEHYDRATION KINETICS OF SOLID STATE COMPOUNDS OF 2-METHOXYBENZYLIDENEPYRUVATE WITH SOME DIVALENT METAL IONS
}

\author{
M. Kobelnik, C. A. Ribeiro, D. S. Dias, G. A. Bernabé, M. S. Crespi. \\ Universidade Estadual Paulista - UNESP - Instituto de Química, CP 355, CEP 14801-970, Araraquara - Brasil.
}

\begin{abstract}
Resumo: o sal de sódio de 2-metoxibenzalpiruvato assim como os complexos metálicos do ligante 2-metoxibenzalpiruvico com os íons $\mathrm{Fe}, \mathrm{Co}, \mathrm{Ni}, \mathrm{Cu}$ e $\mathrm{Zn}$ foram preparados e analisados no estado sólido. Curvas termogravimétricas (TG) destes compostos foram obtidas com massa de amostra em torno de 1 e $5 \mathrm{mg}$ em atmosfera de nitrogênio. Diferentes razões de aquecimento foram utilizadas para caracterizar e estudar estes compostos sob o ponto de vista cinético. A energia de ativação e o fator pré-exponencial foram obtidos com a aplicação, nas curvas TG, do método proposto por Wall-Flynn-Ozawa. Os dados obtidos foram avaliados e os valores obtidos de energia de ativação foram relacionados em função do grau de conversão $(\alpha)$. Os resultados apresentaram que devido a massa de amostras, diferentes energias de ativação foram obtidos. Os resultados também foram discutidos tendo em vista a dependência entre a energia de ativação e o fator pré-exponencial, onde foi verificado o efeito de compensação cinética (KCE) e possível relação linear entre as etapas de desidratação destes compostos.
\end{abstract}

Palavras chave: íons divalentes, 2-metoxibenzalpiruvato; cinética não isotérmica.

\section{Introduction}

2- methoxybenzylidenepyruvate is an organic compound synthesized from piruvic acid and phenyl-substituted compounds [1,2]. Several works have been accomplished with different metal ions starting from these syntheses, since this ligand forms complexes easily. The thermal behavior of these compounds has been evaluated thoroughly, especially by thermogravimetry (TG), differential thermal analysis (DTA) and differential scanning calorimetry (DSC) as well as X-ray powder diffractometry, infrared spectroscopy, which have been used to characterize these compounds [3-9].

The aim of these work is the comparison of the dehydration kinetics using non-isothermal procedures of the solid-state compounds of bivalent $\mathrm{Fe}, \mathrm{Co}, \mathrm{Ni}, \mathrm{Cu}$ and $\mathrm{Zn}$ with 2-methoxybenzylidenepyruvate (2-MeOBP). By applying the isoconversional method proposed by Wall-FlynnOzawa on the TG curves, the data provide information concerning the activation energy $\left(\mathrm{E}_{\mathrm{a}} \mathrm{kJ}\right.$ $\mathrm{mol}^{-1}$ ) versus the conversion degree $(\alpha)$ as well as the pre-exponential factor (ln A min.). Furthermore, the isoconversional method was used as way a of obtaining reliable and consistent kinetic information and also because avoids the use of explicit kinetics models [10].The dependence of the activation energy was also considered in terms of the pre-exponential factor, where it was possible to verify the effect of kinetic compensation (KCE) of these compounds. 


\section{Experimental}

2-methoxybenzylidenepyruvic acid $\left(2-\mathrm{MeO}-\mathrm{BP}^{-} \mathrm{H}^{+}\right)$and its sodium salt, 2-methoxybenzylidenepyruvate (2-MeO-BP-Na+ $)$, were synthesized, purified and prepared, first the acid and then the salt, as described in literature [1]. All the complexes of the general formula $\mathrm{M}^{\mathrm{m}+} \mathrm{L}_{\mathrm{m}} \mathrm{nH}_{2} \mathrm{O}$, where $\mathrm{M}$ are the divalent metal ions $\mathrm{Fe}, \mathrm{Co}, \mathrm{Ni}$, $\mathrm{Cu}, \mathrm{Zn}$ and $\mathrm{L}$ is the sodium salt. The solid-state compounds were prepared by dropwise adding the chlorides of the metal ions to the ligand solution (except for iron, where the sulphate was used) and this was done under continuous stirring until total precipitaton was achieved. The precipites were filtered and washed with water to totally eliminate the chloride (or sulphate) compounds and then dried at room temperature and stored until constant mass in a desiccator over anhydrous calcium chloride.

Kinetic evaluation of the dehydration steps were obtained using heating rates of 5,10 and $20^{\circ} \mathrm{C} \mathrm{min}{ }^{-1}$ from 30 to $500^{\circ} \mathrm{C}$. The curves were obtained using a SDT 2960 thermoanalyser system from TA Instruments Powered samples having a mass of 1 and $5 \mathrm{mg}( \pm 0.05 \mathrm{mg})$ were placed in an alumina crucible, under a nitrogen flow of $100 \mathrm{~mL}$ $\min ^{-1}$

This is compound also was examined using Scanning Electron Microscopy (SEM). The particles were sputtercoated with a thin and uniform layer of gold using a vacuum evaporator and then examined using a JEOL Scanning Microscope, model JSM-T-330A at an accelerating voltage of $20 \mathrm{kV}$

\section{Results and discussion}

In a previous work, these were characterized by simultaneous TG-DTA and DSC curves (in dynamic air atmosphere), infrared spectroscopy and X-ray diffactos and $\mathrm{X}$-ray diffractometry [2]. This compounds are in agreement with the stoichiometry $\mathrm{M}: \mathrm{L}_{2} \mathrm{nH}_{2} \mathrm{O}$ where $\mathrm{M}$ represents the bivalent metal ions, $\mathrm{L}$ is the ligand and $\mathrm{n}$ is the number of water molecu-

The kinetic parameters of dehydration of these compounds were evaluated from the TG curves shown in the Figures 1 and 2.

For the cobalt, nickel and zinc compoun1), the TG curves to first mass loss (een between 30 and $110^{\circ} \mathrm{C}$ shown a paten of dehydration and for the copper $\left(130^{\circ} \mathrm{C}\right)$ and iro $\left(150^{\circ} \mathrm{C}\right)$ compounds (Fig 2), these corespond (150th) cos. (1) ture of thermal decomposition occurs for cobal $\left(185^{\circ} \mathrm{C}\right)$, nickel $\left(240^{\circ} \mathrm{C}\right)$ and zinc $\left(210^{\circ} \mathrm{C}\right)$; while for iron and copper occurs at $130^{\circ} \mathrm{C}$ and $150^{\circ} \mathrm{C}$, respectively. The thermal decomposition in all the TG curves occurs in more than one consecutive step without the formation of stable intermediates or the respective oxides.

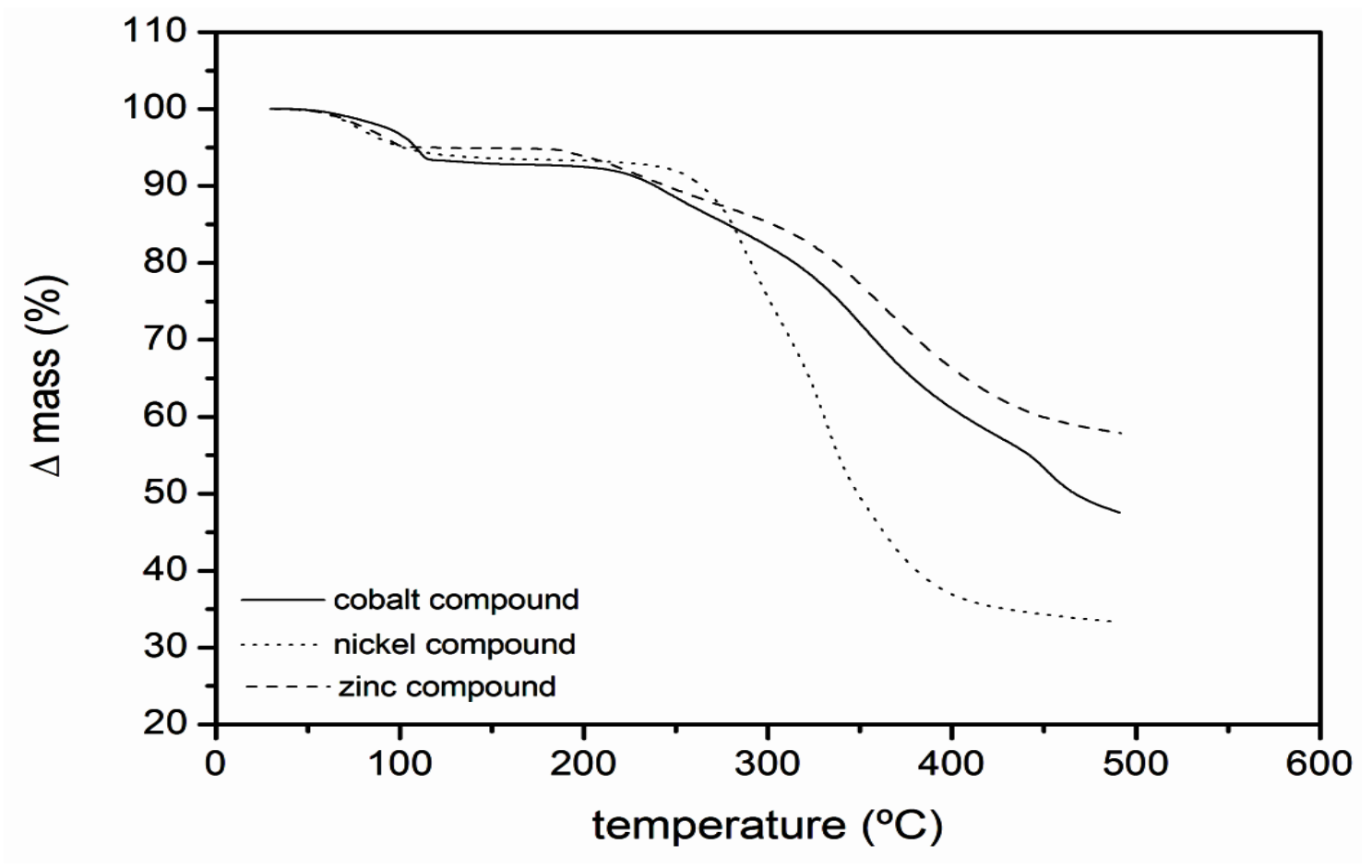

Figure 1. TG curves of the cobalt, nickel and zinc compounds, with mass sample of $1 \mathrm{mg}$, at heating rate of $10^{\circ} \mathrm{C}$ min- 1 in nitrogen atmosphere. 


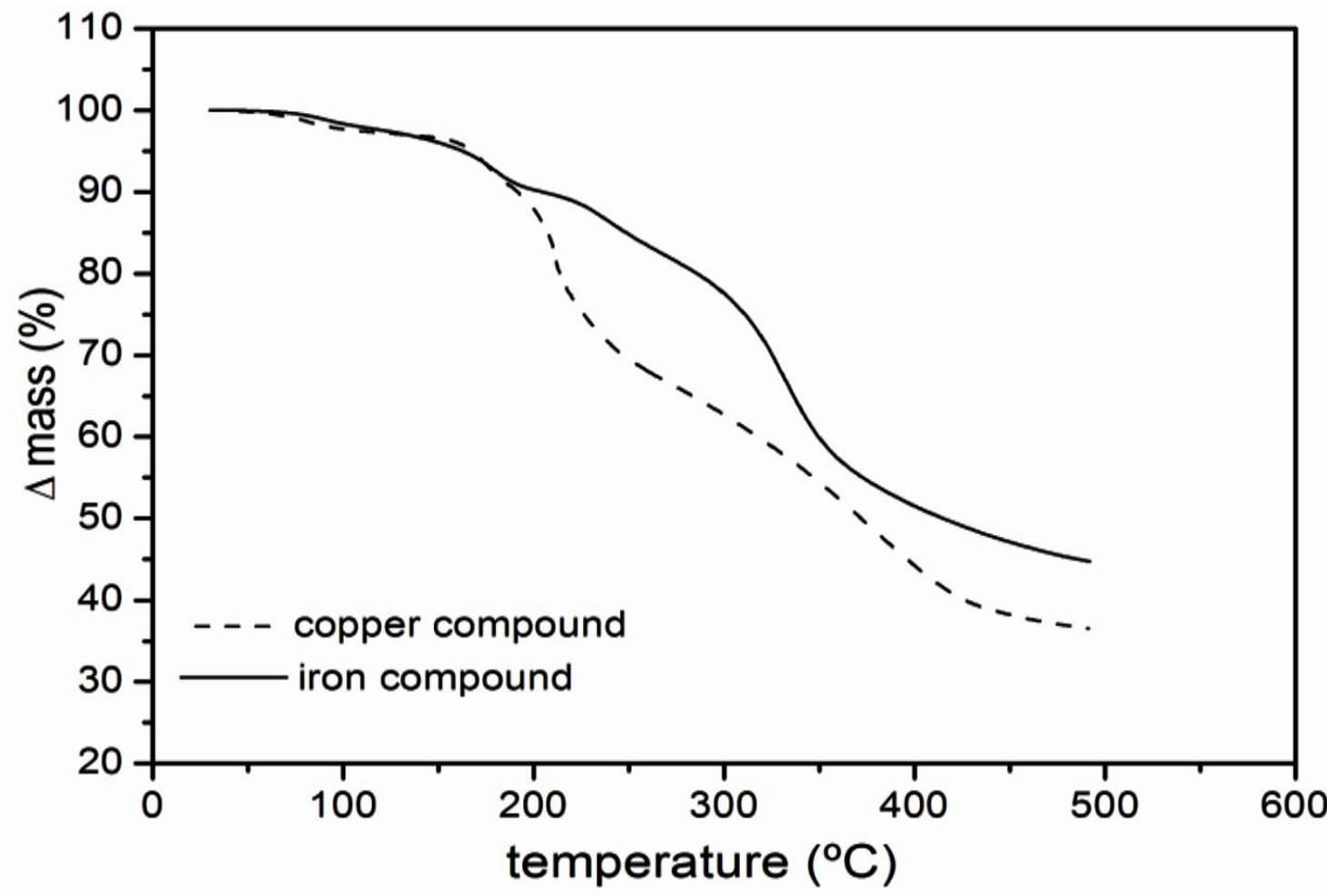

Figure 2. TG curves of the sodium salt, copper, iron and ligand compounds, with mass sample of $1 \mathrm{mg}$, at heating rate of $10^{\circ} \mathrm{C} \mathrm{min}-1$ in nitrogen atmosphere.

The kinetic parameters of the data was obtained using the isoconversional method of Flynn, Wall and Ozawa (FWO) because it is commonly used to avoid the kinetic model $[11,12,13]$. This method is based on fixed values of the degree of conversion $(\alpha)$ obtained from the experiments at different heating rates $(\beta)$ :

$$
\alpha_{t}=\frac{\left(C_{t}-C_{0}\right)}{\left(C_{\infty}-C_{0}\right)}
$$

where $\mathrm{C}$ represents the reagent concentration, as well as other physical properties which are represented in the TG experiment. The subscript corresponds to the elapsed time, $t$, where the initial time is $t=0$ and the final time is $t=\alpha$.

The dependence of $\alpha$ as a function of time can be expressed as the following differential equation [14]:

$$
\frac{d \alpha}{d t}=k(T) \cdot f(\alpha)
$$

where $\mathrm{k}(\mathrm{T})$ is the temperature-dependent rate constant and $\mathrm{f}(\alpha)$ is a function that represents the reaction model. The $\mathrm{k}(\mathrm{T})$ usually employs the $\mathrm{Ar}$ rheinius equation [15]:

$\frac{d \alpha}{d T}=\frac{A}{\beta} \exp \left(-\frac{E}{R T}\right) f(\alpha)$

where $\mathrm{A}$ is the pre-exponential factor, $\mathrm{E}$ is the activation energy and $\mathrm{R}$ is the gas constant.

For dynamic data obtained at a constan heating rate, $\beta=\mathrm{dT} / \mathrm{dt}$, this new term is inserted in the Eq. (3) to obtain the transformation [11]:

$g(\alpha)=\frac{A}{\beta} \int_{0}^{T} \exp \left(-\frac{E}{R T}\right) d T=\frac{A E}{\beta R} p(x)$

Thus, the non isothermal kinetics have resolved the major problem of the isothermal exper- iment, which is that a sample requires some time to reach the experimental temperature undergoing some transformations that are likely to affect the kinetics results [16].

Based on the previous equation and considering that $A, f(\alpha)$ and $E$ are independent of and that $\mathrm{A}$ and $\mathrm{E}$ are independent of $\alpha$, we obtain $[11,16,17]$

$$
g(\alpha)=\frac{A}{\beta} \int_{0}^{T} \exp \left(-\frac{E}{R T}\right) d T=\frac{A E}{\beta R} p(x)
$$

where $\mathrm{x}=(\mathrm{E} / \mathrm{RT})$. For $\mathrm{p}(\mathrm{x})$, where $20 \leq \mathrm{x} \leq 60$ we can use Doyle's approximation of the integra temperature $[11,17,18]$

$$
\log p(x) \cong-2.315-0.4567 x
$$

However, a simpler expression has been developed by the substitution of Eq. (6) into Eq (5) to obtain $[11,17]$

Table 1: Parameters $\mathrm{E}_{\mathrm{a}}\left(\mathrm{kJ} \mathrm{mol}^{-1}\right)$ and the correlation coefficient (r) for the dehydration of the compounds.

\begin{tabular}{cccc}
\hline \multirow{2}{*}{ Compound } & Mass & \multicolumn{2}{c}{ Dehydration } \\
\cline { 3 - 4 } & & $\mathrm{E}\left(\mathrm{kJ} \mathrm{mol}^{-1}\right)$ & $\mathrm{R}^{2}$ \\
\hline \multirow{2}{*}{$\mathrm{Fe}(\mathrm{L})_{2} 0.5 \mathrm{H}_{2} \mathrm{O}$} & $1 \mathrm{mg}$ & $37.0 \pm 0.2$ & 0.99977 \\
& $5 \mathrm{mg}$ & $130.8 \pm 0.3$ & 0.99979 \\
\hline $\mathrm{Co}(\mathrm{L})_{2} 2 \mathrm{H}_{2} \mathrm{O}$ & $1 \mathrm{mg}$ & $141.0 \pm 0.1$ & 0.99979 \\
& $5 \mathrm{mg}$ & $164.2 \pm 0.2$ & 0.99943 \\
\hline $\mathrm{Ni}(\mathrm{L})_{2} 1.5 \mathrm{H}_{2} \mathrm{O}$ & $1 \mathrm{mg}$ & $147.8 \pm 0.1$ & 0.99847 \\
\hline $\mathrm{Cu}(\mathrm{L})_{2} .0 .7 \mathrm{H}_{2} \mathrm{O}$ & $5 \mathrm{mg}$ & $115.4 \pm 0.2$ & 0.99910 \\
\hline \multirow{2}{*}{$\mathrm{Zn}(\mathrm{L})_{2} 2 \mathrm{H}_{2} \mathrm{O}$} & $1 \mathrm{mg}$ & $150.6 \pm 0.1$ & 0.99926 \\
& $5 \mathrm{mg}$ & $120.16 \pm 0.05$ & 0.96818 \\
\hline
\end{tabular}

${ }^{1} \mathrm{~L}=$ ligand 2-methoxybenzilidene ;2Average

$\log g(\alpha) \cong \log \frac{A E}{R}-\log \beta-2.315-0.457 \frac{E}{R T}$

Thus, from the slope of a plot of $\log \beta$ versus $1 / \mathrm{T}$, the activation energy can be calculate for fixed values of $\alpha$ from the experiments at different heating rates testing the constancy of $E$ with respect to $\alpha$ and $\mathrm{T}[11,16,17]$.

The pre-exponential factor can be evaluated taking into account that the reaction is of the first-order and can be defined as [11]:

$$
A=\frac{\beta E}{R T_{m}^{2}} \exp \left(\frac{E}{R T_{m}}\right)
$$

The average values of the activation energy of the kinetics data for all compounds are shown in Table 1, where the resulting correlation coefficient has a good linear close fit, showing that there is good correlation. 
The activation energy $\left(\mathrm{E}_{\mathrm{a}}\right)$ versus conversion degree $(\alpha)$ values for the dehydration are shown in the Figures 3 and 4 .

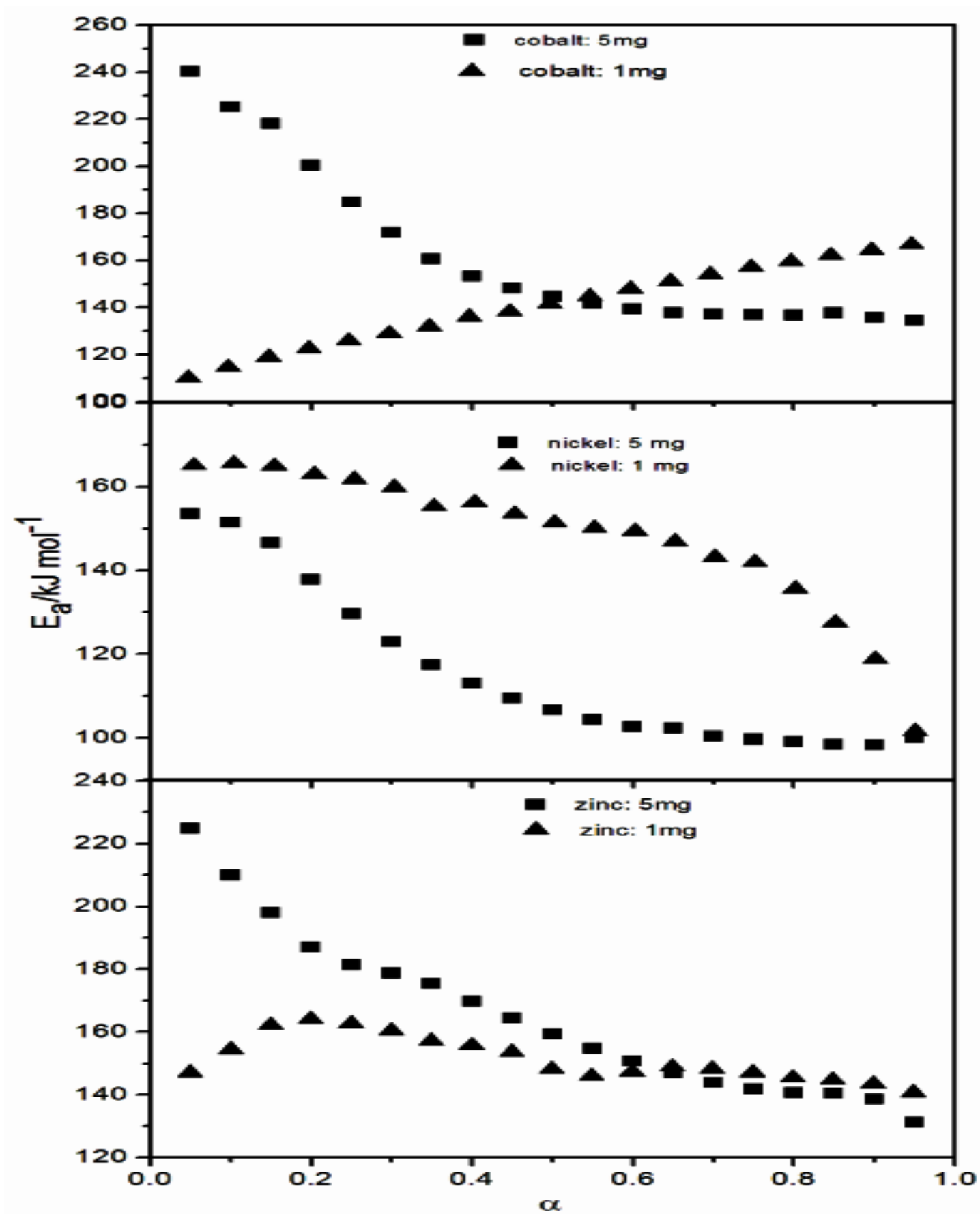

Figure 3. The calculated Ea/kJ mol-1 as a function of $\alpha$ for the dehydration stage of the cobalt, nickel and zinc compounds.

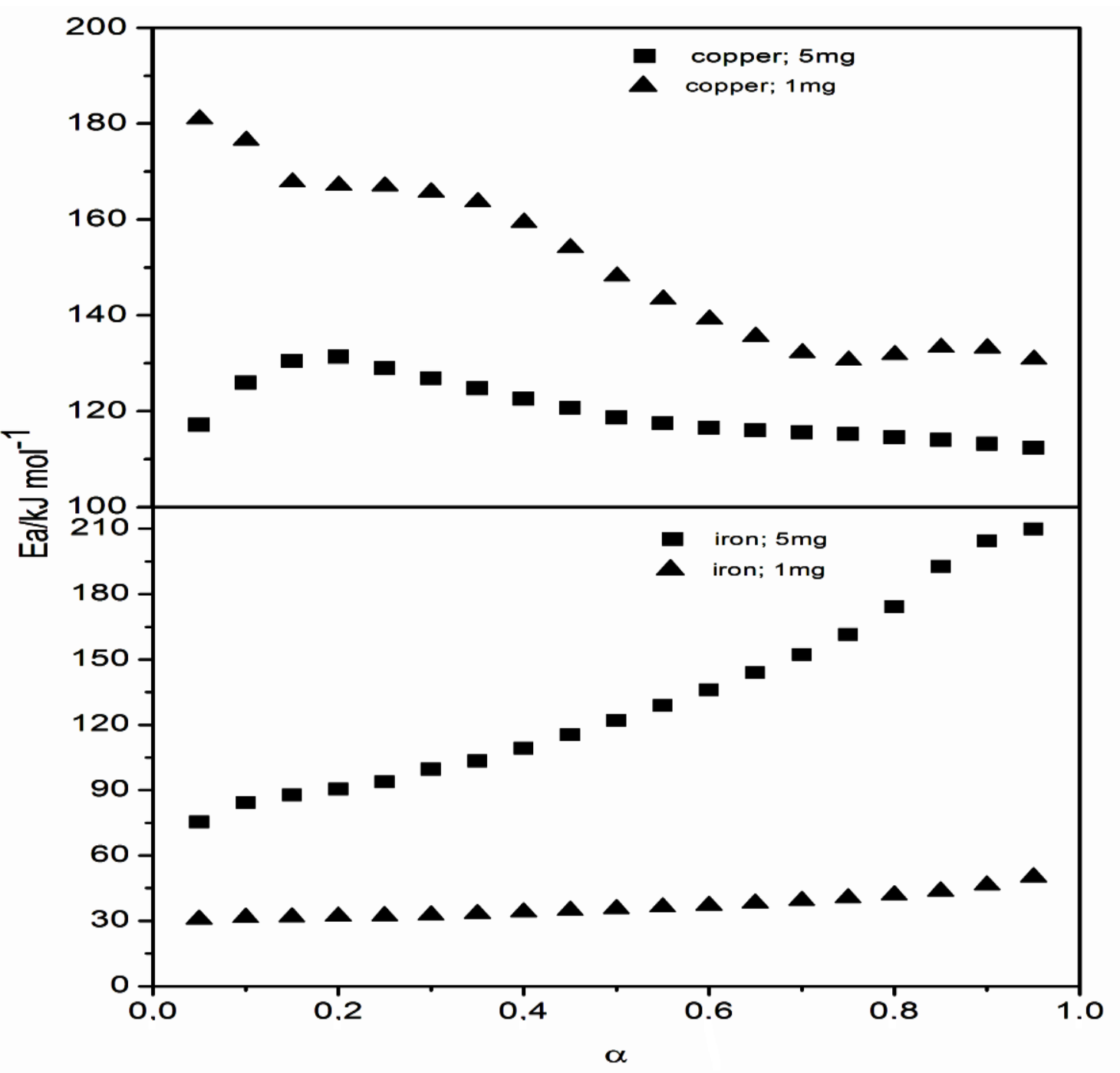

Figure 4. The calculated Ea/kJ mol-1 as a function of $\alpha$ for the dehydration stage of the copper and iron compounds.

For cobalt, nickel and zinc compounds, is dependent of the characteristics of each comwhich apparently has the same dehydration pat- pound. In addition, recently Kobelnik et. al obtern, the values of the activation energy vary for server that different mass sample, the activation each compound. For the masses samples of 5mg, energy continually vary in function of degree conthe dehydration step there are tendencies of the version as numerical values at open and the crimplots maintain the same contour and run parallel ped lids crucibles [18]. Therefore, it suggested that to each other. So this indicates that dehydration these facts favors parallel reactions and besides, kinetic occurs by same way for every extension of the heat of reaction associated with the thermal $\alpha$. However, the mass sample of $1 \mathrm{mg}$, the kinetic conductivity also lead to changes in the reactions. behavior does not occurs in a same tendencies for Furthermore, this not a general rule because the every extension of $\alpha$. These fact were attributed variation of the activation energy depends on sethe differences in the thermal conductivity, which veral factors, such as the type of studied sample, 
the presence or not of cover on the crucible, etc [20-22]. Furthermore, it is clear that the values of activation energy for first dehydration step are variable, which ind . Additionally, the particle size or non-homogeneous particles of each compound can also alter the kinetic behavior. Figures 5 to 8 show SEM images of particles of the cobalt and copper compounds. For the cobalt compound, can be seen different sizes of the particles before and after the diffent sizes of the particles before and after the dehydration. This was attributed to destruction of the structure and subsequent contraction of the sample mass. For the copper compound, can be without destroy the structure. Thus, the activation energy indicates that only the thermal conductivity alters the kinetic behavior.

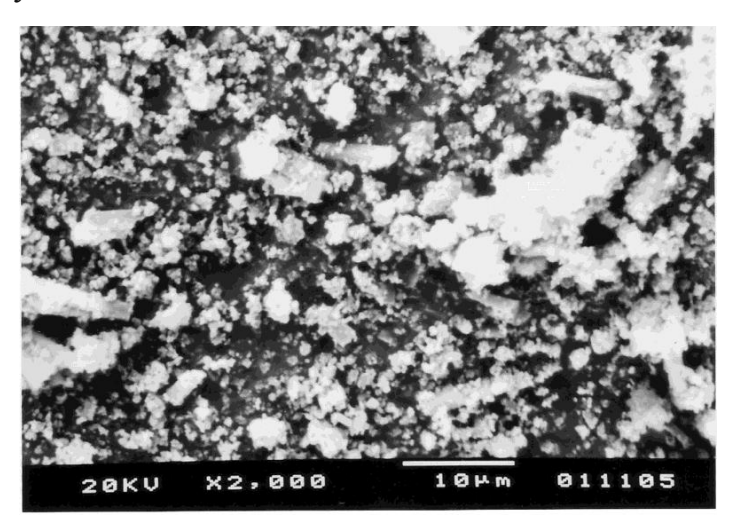

Figure 5. SEM hydrated cobalt compound

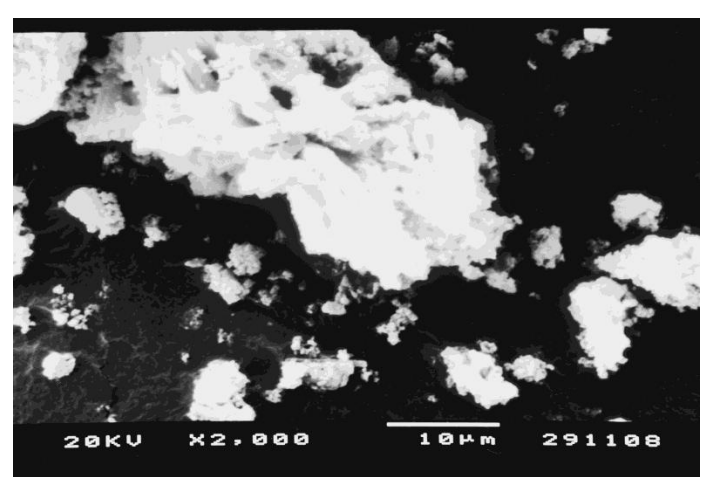

Figure 6. SEM dehydrated cobalt compound

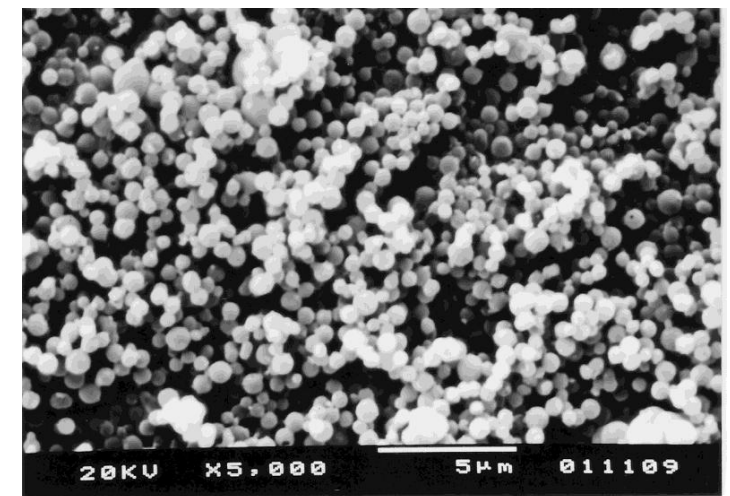

Figure 7. SEM hydrated cooper compound.

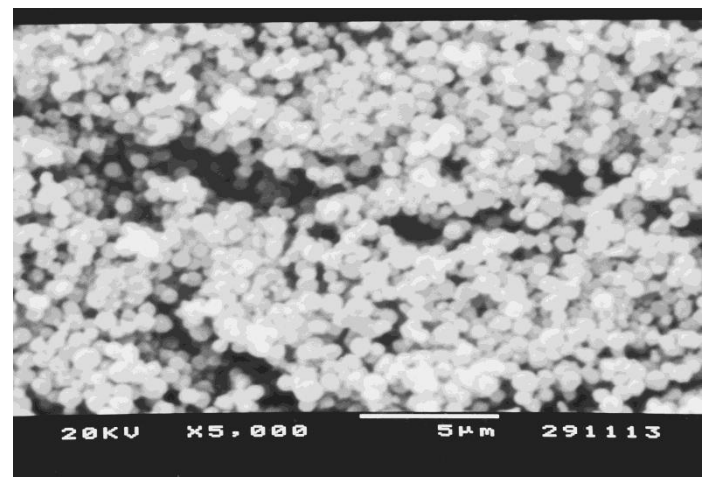

Figure 8. SEM dehydrated copper compound

From the information obtained, we can use the values of the activation energy and the preexponential factor to make the following correlation [23-25]:

\section{$\ln \mathrm{A}=\mathrm{a}+\mathrm{bE}$}

where $\mathrm{a}$ and $\mathrm{b}$ are the compensation constants. The average values found for the plots of the activation energy and pre-exponential factor are commonly called of kinetic compensation effect (KCE). The existence of the "kinetic compensation effect" has been observed in literature for several groups of heterogeneous reactions. The linear relationship between $\ln \mathrm{A}$ and $\mathrm{E}_{\mathrm{a}}$ for the dehydration reactions and thermal decompositio allows us to group them according to their similarities $[23,26]$

For the dehydration, as shown in Figure 9, evidence for the KCE was seen, but there was not relationship between the numbers of water mole- cule losses. Additionally, in Figure 10 e 11, are shown the average values for 1 and $5 \mathrm{mg}$ masses of the activation energy as a function of the pre-exponential factor in a lower $(0.5<\alpha)$ and a higher $(0.5>$ $\alpha)$ range of conversion degree. This artifice was used to demonstrate that there are variations in two intervals of the conversion degree. It may be observed that there was displacement between the cou dehydration.

This demonstrate that even if we just considered the average values of the two intervals, the KCE would not give clear information regarding the dehydration behavior. Additionally, this fact occurs because the dehydration of these compounds also undergoes different steps during the conversion degre $(\alpha)$.

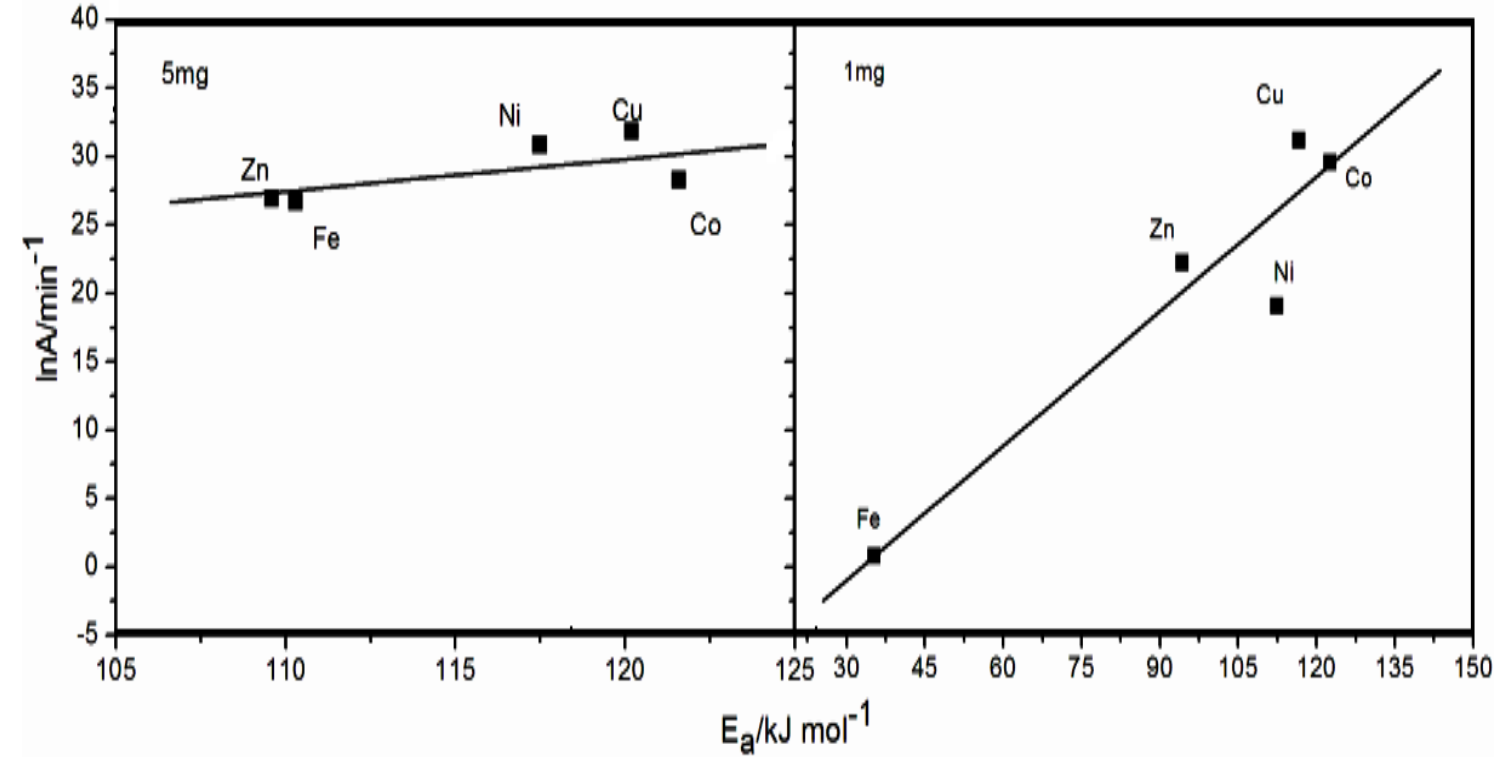

Figure 9. Linear plot of $\ln \mathrm{A} / \mathrm{min}-1$ versus Ea/kJ mol-1 for the dehydration of the compounds: $(\mathrm{A})=1 \mathrm{mg}$ and $(\mathrm{B})=5 \mathrm{mg}$. 


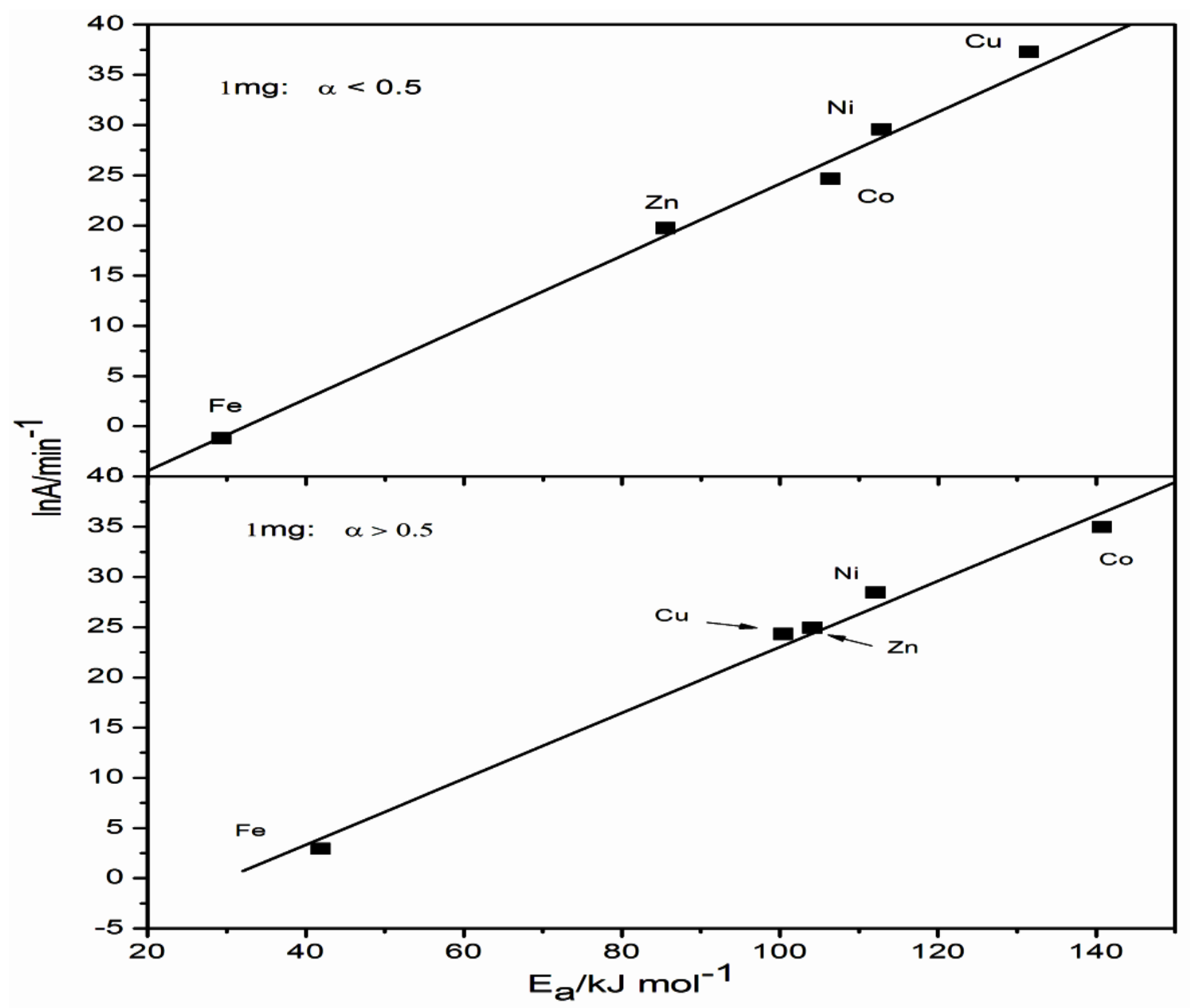

Figure 10. Linear plot of $\ln \mathrm{A} / \mathrm{min}^{-1}$ versus Ea/kJ mol-1 for the dehydration reaction with mass sample of $1 \mathrm{mg}$ in two intervals of conversion degree.

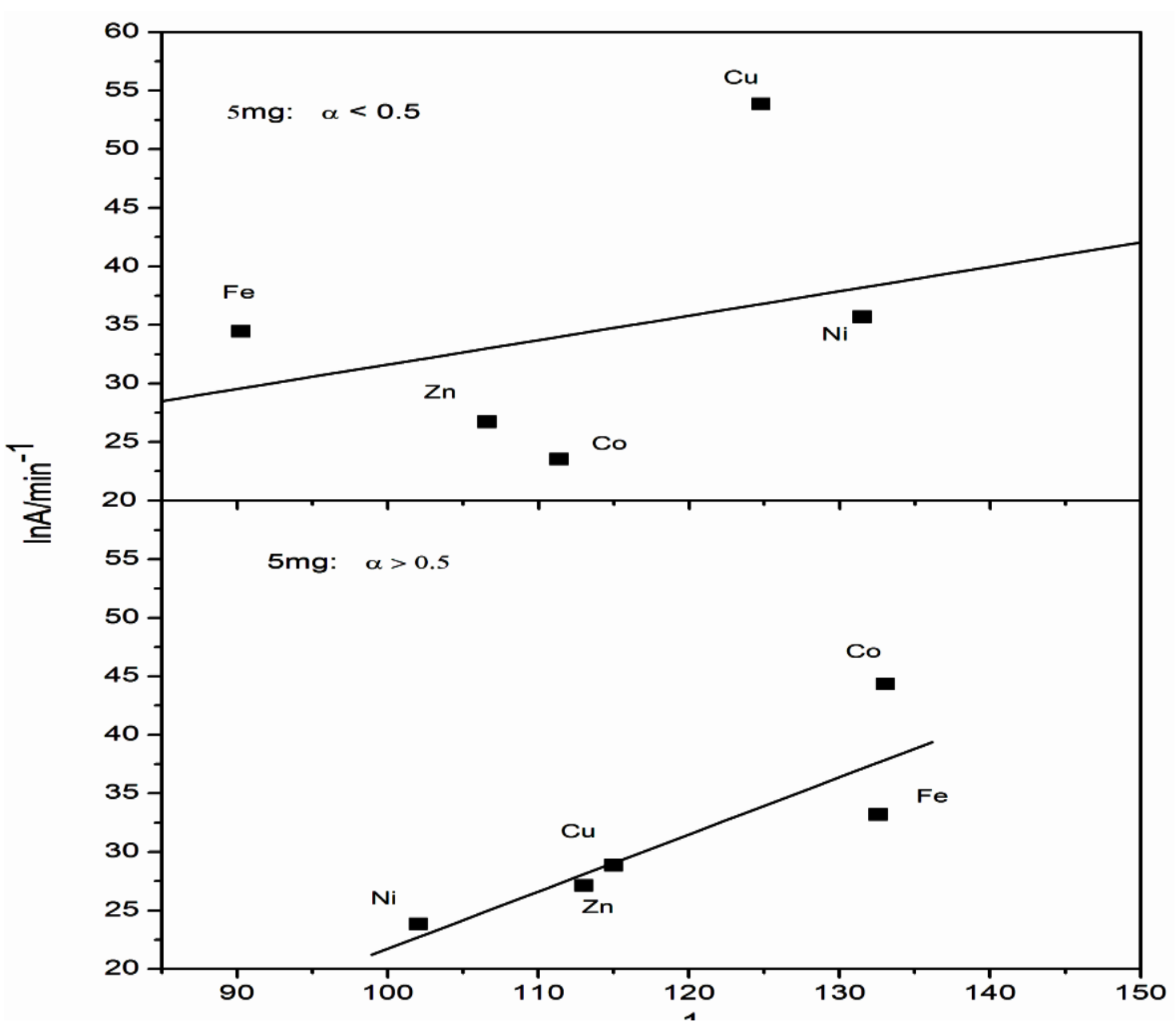

Figure 11. Linear plot of $\ln \mathrm{A} / \mathrm{min}-1$ versus Ea/kJ mol-1 for the dehydration reaction with mass sample of $5 \mathrm{mg}$ in two intervals of conversion degree.

\section{Conclusion}

The presented results clearly showed that the use of the different sample masses, influenced a decrease or an increase of the activation energy (E) values. Besides the kinetic dependence on the (E) a values. Besidion in a dy it can be seen from the resenta it can be seen from kinetic parameters. The activation energy of the dehydrations steps suggests the occurrence of a multi-step process steps. Furthermore, the KCE leaves much doubt as to the reaction type that occurs during the dehydration steps because those compounds are not homogeneous. Thus, the KCE relationships can be used only in an empirical manner, but this is not conclusive to evaluate or determine the complex reaction mechanism.

Acknowledgments

CAPES/CNPQ and IPT - Instituto de Pesquisas Tecnológicas do Estado de São Paulo by TG curves. 
Abstract: Divalent metal complexes of ligand 2-methoxybenzylidenepyruvate with Fe, Co, Ni, $\mathrm{Cu}$ and $\mathrm{Zn}$ as well as sodium salt were synthesized and investigated in the solid state. TG curves of these compounds were obtained with masses sample of 1 and $5 \mathrm{mg}$ under nitrogen atmosphere. Different heating rates were used to characterize and study these compounds from the kinetic point of view. The activation energy and pre-exponential factor were obtained applying the Wall-Flynn-Ozawa method to the TG curves. The obtained data were evaluated and the values of activation energy $\left(\mathrm{E}_{\mathrm{a}} / \mathrm{kJ} \mathrm{mol}^{-1}\right)$ was plotted in function of the conversion degree $(\alpha)$. The results show that due to mass sample, different activation energies were obtained. The results are discussed mainly taking into account the linear dependence between the activation energy and the pre exponential factor, where was verified the effect of kinetic compensation $(\mathrm{KCE})$ and possible linear relations between the dehydrations steps of these compounds.

Keywords: bivalent metal ions, 2-methoxybenzylidenepyruvate, non-isothermal kinetics, dehydration

\section{References}

[1] Reimer, M. and Howard. M. J. Am. Chem. Soc. 50 (1928) 2506.

[2] Kobelnik, M.; Schnitzler, E.; Ionashiro, M. J. Therm. Anal. Cal. 91 (2008) 891.

[3] Fernandes, N. S.; Carvalho Filho, M. A. S.; Mélios, C. B.; Ionashiro, M. J. Therm. Anal. Cal. 59 (2000) 663.

[4] Fernandes, N. S.; Carvalho Filho, M. A. S.; Mélios, C. B.; Ionashiro, M. J. Therm. Anal. Cal 73 (2003) 307.

[5] N. S. Fernandes, S. A. Araujo, M. Ionashiro, Ecl. Quím. 31(2) (2006) 39

[6] Fernandes, N. S.; Carvalho Filho, M. A. S.; Mendes, R. A.; Mélios, C. B.; Ionashiro, M. J. Therm. Anal. Cal. 76 (2004) 193.

[7] A. B. Siqueira, C. T. de Carvalho, E. C. Rodrigues, E. Y. Ionashiro, G. Bannach, M. Ionashiro, Ecl. Quím 32(4) (2007) 49-54.

[8] Ionashiro, E. Y.; Fertonani, F. L.; Mélios, C. B.; Ionashiro, M. J. Therm. Anal. Cal. 79 (2005) 299.

[9] Bannach, G.; Schnitzler, E.; Mélios, C. B.; Ionashiro, M. Ecl. Quim. 29 (2004) 31.

[10] Souza JL, Kobelnik M, Ribeiro CA, Capela JMV. Kinetics study of crystallization of PHB in presence of hydrociacids. J. Therm. Anal. Cal. 97 (2009) 525.

[11] Flynn, J. H.; Wall, J. Nat. Bur. Stand. 70A (1966) 487.

[12] Ozawa, T. Bull. Chem. Soc. Jpn. 38 (1965) 1881.

[13] Ozawa, T. J. Therm. Anal. 2 (1970) 301.

[14] Chen, D.; Gao, X.; Dollimore, D. A. Thermochim. Acta 215 (1993) 109.

[15] Málek, J. Criado, J. M., Sestak, J., Militky, J. Thermochim. Acta 153 (1989) 429.

[16] Vyazovkin, S.; Wight, C. A. Int. Rev. Phys. Chem. 17 (1998) 407.

[17] Flynn, J.H.; Wall, L. A. J. Polymer Sci., Pt. B., 4 (1966) 323.

[18] C.D. Doyle, J. Appl. Polymer Sci. 5 (1961) 285.
[19] Kobelnik, M.; Bernabé, G. A.; Ribeiro, C. A.; Capela, J. M. V.; Fertonani, F. L. J. Therm. Anal. Calorim. 97 (2009) 493.

[20] Galwey A. K.; Brown M. E. Thermal Decompositions of Ionic Solids. $1^{\text {th }}$ ed. Amsterdan: Elsevier; 1999.

[21] Galwey A. K. Thermochim. Acta. 2004,413,139.

[22] Prasad, T. P.; Kanungo, S. B.; Ray, H. S. Thermochim. Acta. 2002,203,503.

[23] N. Koga, J. Sestak. J. Therm. Anal. 37 (1991) 1103.

[24] N. Koga. Thermochim. Acta 244 (1994) 1.

[25] J. Zsakó. J. Therm. Anal. Cal. 47 (1996) 1679.

[26] J. G. R. Poço; H., Furlan; R., Giudici. Journal Physical Chemical B 106 (2002) 4873. 